\title{
59-Yabancı dil eğitiminde görsel ve işitsel çevirinin etkileri
}

Erdem KOÇı

APA: Koç, E. (2020). Yabancı dil eğitiminde görsel ve işitsel çevirinin etkileri. RumeliDE Dil ve Edebiyat Araşttrmaları Dergisi, (Ö8), 758-772. DOI: 10.29000/rumelide.821965.

Yabancı dil öğreniminde çevirinin rolü uzun zamandır tartışma konusu olmuştur. CFRL'nin (Avrupa Dilleri Ortak Çerçeve Programı) 2001 yılında yayınlanan bildirisinde, yabancı dil öğrenen öğrencilerin "alım, üretim, etkileşim veya arabuluculuk" gibi çeşitli dil etkinliklerini gerçekleştirirken özellikle sözlü ve yazılı çeviri faaliyetlerinin iletişimsel dil yeterliliklerini aktive ettiği vurgulanmıştır. Görsel-İşitsel çeviri, sözlü dilin görsel-işitsel medyaya aktarılmasını ifade eder ve genel olarak "ekran çevirisi”, "multimedya çevirisi” veya film çevirisi terimlerini ifade etmek için bir şemsiye terim olarak kullanılır (Perego, 2005; Chiaro, 2009; Bollettieri, Di Giovanni and Rossato, 2014). Görsel-işitsel çeviri'nin dil öğrenimi ve öğretimine iletişimsel bir yaklaşımla entegrasyonuna ilgi artmaktadır ve bu disiplin artık çeviri çalışmaları alanındaki en hızlı büyüyen alanlardan biri olarak kabul edilmektedir. Altyazı çalışması yabancı dil öğrencilerinin dinleme, okuma ve yazma becerilerini geliştirerek, aktarılabilir becerilerini geliştirebilmelerine olanak sağlar. Sözlü dil aktarım yöntemi, öğrencilere dublaj, sesli açlklama ve diğer seslendirme görevleri aracılığıyla konuşma becerilerini geliştirme firsatı sunar. Bu alanda yapılan çeviri faaliyetleri, hem bireysel olarak hem de gruplar halinde gerçekleştirilebilen ve böylece hem bireysel hem de işbirlikçi öğrenmeyi teşvik eden öğrenci merkezli bir potansiyeline sahiptir. Bu çalışmanın amacı, görselişitsel çevirinin özellikle altyazı çevirisinin eğitim faaliyetlerine dâhil edilerek hedeflenen yabancı dili öğrenmede sağlayacağı katkıların daha fazla araştırılmasını teşvik etmektir. Araştırma yöntemi olarak, nitel ve nicel yöntemler bir sentez halinde kullanılarak, özellikle son yirmi yıldaki teknolojik gelişmelere bağlı olarak görsel-işitsel çeviri alanındaki literatür taraması yapılacak, betimsel model üzerinden bu alandaki uygulamaların mevcut durumları da göz önünde bulundurularak, yabancı dil eğitiminde sağlayacağı katkılar ortaya koyulmaya çalışılacaktır.

Anahtar kelimeler: Görsel ve işitsel çeviri, altyazı çevirisi, yabancı dil eğitimi

\section{Effects of audio-visual translation in foreign language education}

\begin{abstract}
The role of translation in foreign language learning has long been a topic of discussion. In the statement of CFRL (Common European Framework of Reference for Languages) published in 2001, it was emphasized that especially the oral and written translation activities activate the communicative language competencies of the students who learn foreign languages while performing various language activities such as "recruitment, production, interaction or mediation". Audiovisual translation refers to the transfer of spoken language to audiovisual media and is commonly used as an umbrella term to refer to the terms "screen translation", "multimedia translation" or film translation (Perego, 2005; Chiaro, 2009; Bollettieri, Di Giovanni and Rossato,
\end{abstract}

Öğr. Gör. Dr., ,İstanbul Aydın Üniversitesi, Anadolu Bil Meslek Yüksekokulu, Uygulamalı İngilizce ve Çevirmenlik Programı (İstanbul, Türkiye), erdemkoch@hotmail.com, ORCID ID: oooo-ooo3-3164-9796 [Makale kayıt tarihi: 11.09.2020-kabul tarihi: 20.11.2020; DOI: 10.29000/rumelide.821965] e-posta: editor@rumelide.com 
2014). Rapid technological changes in the last two decades have created new methods and opportunities in language learning. However, there is increasing interest in integrating Audiovisual Translation into language learning and teaching with a communicative approach, and this discipline is now recognized as one of the fastest growing fields in Translation Studies. Audiovisual translation; subtitling (written language transfer method) and revoicing (oral language transfer method). Subtitling allows students to add a written translation of the original visual language (interlanguage captioning) or a text to an Audiovisual product. Revoicing (the oral language transfer method) offers students the opportunity to improve their speaking skills through dubbing, voice annotation, and other vocalization tasks. Copying enables students to replace the sound in an audiovisual product with their own. Dubbing, which includes lip sync in professional practice, can also improve animation, listening, reading and writing skills depending on the task undertaken. Audio-visual translation activities have a student-centered potential that can be performed both individually and in groups, thus promoting both individual and collaborative learning. The aim of this study is to encourage further research on the contribution of audiovisual translation, especially subtitle translation, to learning the targeted foreign language by incorporating it into educational activities. As a research method, by using qualitative and quantitative methods as a synthesis, a literature review in the field of audio-visual translation will be conducted, especially depending on the technological developments in the last twenty years, through the descriptive model, the contributions of audio-visual translation applications in foreign language education will be tried to be revealed by considering the current situation.

Keywords: Visual and audio translation, subtitle translation, foreign language education

\section{Giriş}

Çeviri, "bir metnin anlamının yazarların metni amaçladığı şekilde başka bir dile aktarılması" (Newmark, 1988, s. 5) olarak tanımlanmıştır. İlkyazı kadar eski olmasına rağmen, "çeviri çalışmaları" terimi ilk kez 1970'lerde kullanılmıştır. Talavan (2016), herhangi bir multimedya ürünü üzerinde yapılan çeviri çalışmalarının bireylerde dilbilgisi ve yorum gücünü geliştirdiğini söylemektedir. Görsel ve işitsel çevirinin en belirgin özelliği birden çok kanalı (işitsel ve görsel) içerir; farklı sinyal türleri (hareketli görüntüler, sabit görüntüler, metinler, diyalog, anlatım, müzik, gürültü); ve çevrilen ürün ile izleyici arasında bir köprü kurarak, çevrilmiş ürünü, orijinal bir ürün olarak algılanmasını sağlar (Mayoral, 2002).

Görsel ve İşitsel Çeviri, sözlü dilin görsel-işitsel medyaya transferini ifade eder ve genel olarak 'ekran çevirisi,', 'film çevirisi' veya 'multimedya çevirisi' anlamına gelen bir çatı ifade olarak kullanılır (Perego, 2005) Chiaro, 2009; Bollettieri, Di Giovanni ve Rossato, 2014). Son yirmi yllda akademisyenlerin Görsel ve İşitsel çeviriye artan ilgisi sayesinde, bu disiplin artık "Çeviri Çalışmaları alanındaki en hızlı büyüyen alanlardan biri” olarak tanınmaktadır (Dỉaz Cintas, 2008: 1). Görsel ve İşitsel çeviri, iletişimsel bir perspektif içinde etkili bir şekilde kullanılabilecek bir arabuluculuk faaliyeti olarak düşünülmektedir. Bu iki ana türe ayrılabilir: altyazı (yazılı dil aktarım yöntemi) ve sözlü dil aktarım yöntemi (revoicing). Altyazı, sözlü metnin yazılı çevirisi (interlingual) veya iki yönlü veya aynı dil olarak da adlandırlan sözlü metnin yoğunlaştırılmış biçimde sesin yazıya dönüştürülmesi (intralingual) olabilen altyazı uygulamasını içerir. Buna ek olarak, dil öğrenmede iki dil arası altyazı kombinasyonu düşünülmektedir: standart ve ters. Standart altyazı, yazılı ilk dile çevrilmiş konuşulan ikinci dil metnini ifade ederken, ters altyazı, yazılıya çevrilmiş konuşulan metni ifade eder. Sözlü dil e-posta: editor@rumelide.com 
aktarım yöntemi(revoicing) ise; dublaj, seslendirme, anlatım, sesli açıklama ve yorumlamayı içerir (Pérez González, 2009).

Avrupa Birliği, altyazı faaliyetlerini yürütmek için özel olarak yazılım tasarlayan LEViS (Altyazılar Yoluyla Öğrenme) projesine finansman sağlayarak Görsel ve İşitsel yöntemin dil öğrenme sürecine katkısını resmi olarak tanımıştır (Sokoli, 2006; Sokoli ve ark., 2011) ve daha yakın zamanda Hayat boyu Öğrenme Programı (2011-2014) kapsamındaki ClipFlair projesini destekleme kararı almıştır. Altyazıya dayalı öğrenme (LEVIS) deneyimine dayanan ClipFlair, etkileşimli klip altyazı (altyazı ve video ek açıklamaları) ve açığa çıkarma (sesli açıklama, dublaj ve okuma) yoluyla dil öğrenimini desteklemeyi amaçlamaktadır. Projeden çıkan dil öğrenme web platformu, ders planları ve ilgili meta verilerle tamamlanan, sınıf, uzaktan ve kendi kendine öğrenme gibi farklı öğrenme bağlamları için uygun Görsel ve İşitsel (Audio Visual Translation) etkinlikleri sunmaktadır (Baños ve Sokoli, 2015:Incalcaterra McLoughlin ve Lertola, 2015: Sokoli, 2015). ClipFlair projesi, dublaj ve sesli açıklama dâhil olmak üzere diğer Görsel-İşitsel Çeviri (AVT) modlarının yanı sıra dil öğreniminde altyazı kullanımını teşvik etmektir.

Günümüzde altyazı, artık dil öğrenimini geliştirebilecek yenilikçi bir öğretim aracı olarak kabul edilmektedir. Dil öğrenenleri görsel-işitsel bir sürece dâhil ederken, onları özgün dilde sözlü ve yazılı diyaloğa maruz bırakır. Altyazı, dil becerilerini (dinleme, okuma ve yazma) ve aktarılabilir becerileri (dijital okuryazarlık gibi) geliştirme, anımsatmayı kolaylaştırma ve iletişimin pragmatik yönlerinin yanı sıra kültürel ve kültürlerarası konular hakkında da farkındalık yaratma potansiyeline sahiptir. Bununla birlikte, bireyin motivasyonunu artırmaya ve genel öğrenme deneyimini geliştirmeye de yardımcı olabilir. Pedagojik bir araç olarak altyazı uygulaması üzerine araştırmalar hala sınırlı olsa da, bu alana gösterilen ilgi gün geçtikçe artmaktadır. Yapılan çalışmalar, altyazı kullanımının ikinci dil ediniminde kelime dağarcığının gelişmesinde (Williams \& Thorne, 2000),deyimlerin tanınması ve üretilmesinde (Bravo, 2008), pragmatik farkındalık kazanılmasında (Incalcaterra McLoughlin, 2009) ve dinlediğini anlamada önemli gelişmeler sağladığını ortaya koymuştur (Talaván, 2010, 2011). Incalcaterra McLoughlin ve Lertola (2011), dil sinıfinda uygulanacak metodoloji temelli bir alt yazı modeli önerirken, Borghetti (2011) kültürlerarası yeterliliği artırmak için özel olarak alt yazı kullanılabileceğini belirtmektedir.

Çalışmanın 1.bölümünde dilbilgisi-çeviri yöntemi ele alınmış olup, 2.bölümde yabancı dil öğretiminde çevirinin rolüne değinilmiştir, 3.bölümde yabancı dil eğitiminde görsel ve işitsel çevirinin etkileri incelenip, sonuç bölümünde elde edilen bulgulardan bir sentez yapılmaya çalışılmıştır.

\section{Dilbilgisi-çeviri yöntemi}

Tarihsel geçmişe baktığımızda, 16.yüzyılda İngilizce, Fransızca ve İtalyanca gibi modern dillerin siyasal nedenlerle önem kazanmaya başladığı görülmektedir. Bu diller, ikinci dil edinimi ihtiyacı nedeniyle 18. yüzyılda Avrupa'daki birçok okulda müfredata dâhil edilmiştir. O zamana kadar en çok çalışılan dil olan Latince ikinci dil olarak öğretilmeye başlanmıştır. Öğretim yöntem ve tekniği bağlamında ana odak olarak kuralların incelenmesi yoluyla dilbilgisi, örnek cümleler ve çeviri yoluyla yazma pratiği uygulanmaktaydı. Klasik dil öğretimine dayanan bu yaklaşım 19. yüzyılda da benimsenmiş ve Dilbilgisi-Çeviri yöntemi veya geleneksel yöntem olarak literatüre geçmiştir.

Dilbilgisi-çeviri yönteminde dil öğrenmenin amacı, hedef dilde edebi metinleri okuyabilmek veya dil öğrenmenin zihinsel uygulamasından yararlanabilmek olmuştur. Dilbilgisi, belli bir müfredat 
dâhilinde sistematik bir sırayla öğretilen dilbilgisi kurallarının sunumu ve ezberlenmesiyle tümdengelim yöntemiyle öğrenilmektedir. Bu kurallar genellikle kısa metinlerde veya ağırlıklı olarak edebi metinlerde yer alan cümlelerin çevrilmesiyle öğretilmeye çalışlır. Bu nedenle odak okuma ve yazma üzerinedir ve dinleme ile konuşmaya neredeyse hiç dikkat edilmemektedir. Öğretimin ve dil pratiğinin temel birimi cümledir ve cümleye odaklanmak dilbilgisi-çeviri yönteminin karakteristik bir özelliği olarak ön plana çımaktadır.

Dilbilgisi-çeviri yöntemi, 1840'lardan 1940'lara kadar Avrupa'da en yaygın yöntem olarak kabul edilmiştir. (Richards ve Rodgers, 2001). Bu yöntem kuşkusuz dil öğreniminde gerekli olup olumlu bir etkiye sahiptir. Öte yandan dijital çağı yaşadığımız günümüz koşullarında ihtiyaca cevap verdiğini söylemek yeterli değildir.

\subsection{Dilbilgisi - çeviri yöntemindeki gelişmeler}

19. yüzyılın sonları, dil öğretimine alternatif yaklaşımlar geliştiren akademisyenlerin ve dilbilimcilerin önderlik ettiği reform hareketinin ortaya çlktığı dönem olmuştur. Reform hareketi Doğal Yöntemi ve Doğrudan Yöntemi içermekteydi. Bu yeni yöntemlerin temeli, konuşma dili, fonetik üzerine daha fazla odaklanma, dilbilgisi öğrenimine tümevarımsal bir yaklaşım ve yabancı dilin daha fazla kullanılması yoluyla modern yabancı dillerin öğretiminin geliştirilmesine dayanıyordu (Richards ve Rodgers, 2001).

Almanca ve İngilizce öğretmeni olan Wilheim Viëtor (1850-1918), Dilbilgisi-Çeviri yönteminin dil öğretimindeki yetersiz olduğunu açıklayarak Almanya'da reform hareketini başlattı. Onun görüşleri daha sonra yaygınlaşan Direkt Yöntem' e esas teşkil etmiştir. (Howatt 1984; Howatt ve Smith, 2002). Derste anadilini yasaklamak, çeviriye hiçbir şekilde başvurmamak, fonetikten yararlanmak, edebi metin yerine günlük dilde yazılmış metinler kullanmak, dilbilgisi kurallarını öğrencilerin bulmasını istemek gibi o günler için radikal öneriler getirildi. İngilizce dilbilimci Henry Sweet (1899), araştırma ve pratik çalışmaların ilerlemesine giden yolu göstermek ve "mevcut koşullardan" en iyi şekilde yararlanmaya çalışmak için dil öğretiminde yenilikçi ilkeler sundu. Uluslararası Fonetik Alfabesinin destekleyicilerinden biri olan Sweet, tüm dillerin fonetik üzerine çalışmasını temel aldı ve edebi metinlerden ziyade konuşma diline yoğunlaşmayı teşvik etti.

Jespersen (1904), çeviri ya da çeviri becerisinin yabancı dil öğretiminin amacı olmadığını kabul etmenin yanı sıra, “çevirinin dil öğretiminde yararlı ve vazgeçilmez bir araç olabileceğini” belirtmiş ve faydalanabilecek 4 yöntem önermiştir;

(a) Çeviri vasıtasıyla öğrencilerin bir kelimenin veya bir cümlenin anlamını kavrayabilmesi,

(b) Hedef dildeki bir cümlenin çevirisini anadile tercümesi yaptırılarak kavratılması,

(c) Öğrencilere hedef dilde uygulama firsatı veren anadilden çeviri,

(d) Eğitimcilere öğrencilerin edindiği bilgileri ölçme firsatı veren anadilden hedef dile yazılı ve sözlü çeviri.

Jespersen, öğrencilere kelimelerin anlamını kavrayabilmek için alternatif olarak nesnelerin doğrudan gözlenmesi, resimler aracılığıyla algının arabuluculuğu, hedef dilde bağlamdan ve tanımlardan anlam çıarması yöntemlerinin de faydalı olabileceği tavsiyesinde bulunmuştur. Bir İngiliz bilim insanı ve İkinci Dil Olarak İngilizce (ESL) üzerine birçok kitap ve makalenin yazarı Harold E. Palmer, dilbilim, 
psikoloji ve pedagojiye dayalı birçoklu öğretim metodolojisi önermektedir. Palmer (1917), ESL kursları için sözlü dil içeriğinin kavranmasını geliştirmeye çalışmıştır. Bu yaklaşım yaygın olarak Sözlü Yaklaşım veya Durumsal Dil Öğretimi olarak bilinmektedir. Tüm sözlü dil etkinlikleri, öğrencilere konuşma pratiği için birçok fırsat sağlamak amacıyla sunulmaktadır. Jespersen çeviriyi, sözcügün anlam ile ilişkilendirilmesi, tanımı ve bağlamı ile birlikte aktarmanın etkili bir yolu olarak değerlendirmekteydi.

19. yüzyılın sonlarına doğru Dilbilgisi-Çeviri yöntemine güçlü itirazlar yapılmaya başlanmıştır. Bunun nedeni, sözlü kavrayışın göz ardı ediliyor olması ve hedef dilde sözlü uygulamaların yerine edebi metinlerin kullanımının ön planda olmasıydı. Yaygın olan görüşe göre de, çevirinin özü itibariyle dilbilgisi-çeviri yönteminin bir tamamlayıcısı olduğu ve bunun yanı sıra öğrencilerin de öğrendikleri bilgileri sınamanın önemli bir yolu olarak çeviriye başvurabilecekleri savunulmaktaydı.

Bağlamdan arındırılmış cümlelerin kullanılması ve dilbilgisi çeviri yönteminin uygulanmasıyla teşvik edilen uzun kelime listelerinin ezberlenmesi nedeniyle de bazı bilim insanları Yabancı Dil sınıfına çevirinin dâhil edilmesine karşı çıkmıştır (Lado, 1957; Richards \& Rodgers, 1986). Ana argümanları, ana dil kullanımının sözdizimsel hatalara yol açabileceği ve dilbilgisi yapılarını öğrenmeye odaklanarak iletişim becerilerinin gelişimini yavaşlatacağı inancına dayanıyordu.

\section{2. İletişimsel dil öğretimi}

1950 ile 1980 arasındaki dönem, dil öğretiminde yaklaşım ve yöntemlerin tarihindeki en hareketli dönemler arasındaki yerini almıştır. Bunlardan biri de İşitsel Dil Yöntemiydi ve Amerikan Ordusu Uzmanlık Eğitim Programı ve Yapısal Yaklaşımın mantıksal bir gelişımi olarak ortaya çımıştır (Fries, 1945; Lado, 1957). Yapısal dilbilim ve davranışçı psikolojiye dayanan İşitsel Dil Yöntemi, öğrenilecek bir dizi alışkanlıktan oluşan sözlü dile odaklanmıştır. Skinner'a (1957) göre dil sözlü davranıştır ve sözel olmayan davranıştan farklı değildir. Bu nedenle, dil öğrenimini de kapsayan herhangi bir öğrenme süreci, bir uyaran vasıtasıyla pekiştirme tarafından takip edilen tepki davranışını tetiklediğinde gerçekleşebilmektedir.

İngiliz dilbilimci Wilkins $(1972,1976)$, dilin öğrencilerin anlaması ve ifade etmesi gereken iletişime dayalı evrensel anlamlardan oluştuğunu ileri sürmüştür. Wilkins iki tür anlam tanımlaması yapmıştır; "Kavramsal" kategoriler (zaman, miktar, konum vb.) ve "iletişimsel işlev" kategoriler (talepler, ret, şikâyetler vb.). Kavramsal ve işlevsel içerik anlayışına göre yabancı dil eğitimi sadece dil bilgisi yapılarına göre değil iletişim gerekliliklerine göre de düzenlenmelidir.

Avrupa Konseyi, iletişimsel yeterliliği geliştirmek için dil öğrenme hedeflerini belirten yeni bir dil müfredatı olan Wilkins’in kavramsal görüşünü uygulamıştır (Ek \& Trim, 1990). Avrupa Konseyi'nin çalışmaları ve özellikle Wilkins’in katkısı, İletişimsel Dil Öğretiminin gelişimini önemli ölçüde etkilemiştir. Bu kavram aslında 1970'lerde Hymes (1972)'nn "İletişimsel Yeterlilik" teorisine ek olarak dil kullanımı becerisini desteklemektedir. İletişimsel Dil Öğretimi yönteminin temel ilkeleri geniş çapta kabul görmüşş çeşitli eğitim uygulamalarında kullanılmaya başlamıştır.

İletişimsel Dil Öğretiminin temel ilkelerine göre (Finocchiaro \& Brumfit 1983, Richards \& Rodgers, 2001);

a) Anlam her şeyden önemlidir, 
b) Dil öğrenimi, iletişim kurmayı öğrenmektir,

c) Etkili iletişim ve anlaşılır telaffuza dikkat edilmelidir,

e) Öğrencilerin dil öğrenimine katkı sağlayacak araçlar kullanılmalıdır,

f) Öğrencilerin ihtiyaç duyduğu yerlerde çeviri kullanılabilir,

Eğitimciler dil eğitiminde motive edici yöntemler kullanmalıdır.

Bu ilkeler yabancı dil eğitiminde çeşitli aktivitelerin uygulanmasını teşvik eder ve altyazı çalışmaları da bunlardan birisi olarak düşünülebilir. Altyazı, öğrencilerin anadilden hedef dile veya hedef dilden anadile yaptıkları çevirileri mantıklı bir şekilde kullanarak iletişim kurmalarına katkı sağlar ve iletişimsel yetkinliklerini geliştirir.

\section{Yabancı dil öğretiminde çeviri}

Son on yılda, akademisyenler arasında Dil Öğretiminde Çeviri bağlamında yeni bir ilgi ortaya çıkmıştır. G. Cook'a (2010) göre, neredeyse bir asırlık yokluğun ardından artık Dil Öğretiminde Çevirinin yeniden canlanma zamanı gelmiştir. Bu, hiçbir şekilde Dilbilgisi-Çeviri Yöntemi'nin yeniden canlandırılması değil, iletişimsel bir yaklaşıma dayalı dil öğretiminde çevirinin bir uygulamasıdır (Zojer, 2009).İkinci Dil Ediniminde çevirinin yararları konusunda çok az deneysel araştırma olmasına rağmen, son araştırmalar yabancı dil derslerinde çevirinin kullanımını teşvik etmiştir (Malmkjaer, 1998; Stoddart, 2000; Laviosa ve Cleverton, 2006; Witte ve diğerleri, 2009; Incalcaterra McLoughlin \& Lertola, 2015).

Çevirinin akademik söylemden uzun süre dışlanmasının nedenleri esas olarak sosyo-politik faktörlerden ve köklü öğretim alışkanlıklarından kaynaklanmaktadır. Ne yazık ki bu yaygın yanılgılar çevirinin büyük ölçüde göz ardı edilmesine neden olmuştur. G. Cook (2007), çevirinin akademik literatürde uzun zamandır reddedilmiş olsa da, bilinmeyi anlamaya çalışan dil öğrencilerinin daima öğrenme yöntemleri içerisindeki önemini korumayı başarmış olduğunu belirtmektedir.

Aslında, oldukça yaygın olarak iletişimsel görevleri yerine getirirken, öğrenciler bir cümlenin anadilde neyi ifade etmek istediğini düşünme ve sonra bunu yabancı dilde söyleme eğilimindedirler. Bazen de öğretmenden cümleyi tamamlamak için bilmedikleri ancak ihtiyaç duydukları sözcüksel öğe veya ifadenin yabancı dildeki karşılı̆̆ını yani çevirisini sorarlar (Atkinson, 1987). Bu açıdan, öğrencilerin anadilini etkin bir şekilde kullanabilmesi, çeviri uygulamasına dayalı öğrenmede stratejik bir öneme sahiptir.

Öte yandan, çeviri etkinlikleri yabancı dil sınıflarında öğrenciler açısından, öğrendikleri yabancı kelimeleri ve cümle yapılarını uygulama firsatı sunan ortamlardır. Anadili ve yabancı dili karşılaştırabilmek, dilbilgisi ve sözcük yapıları arasındaki farkları kavrayabilmek, öğrencilere olumlu yönde motivasyon sağlamaktadır (Deller \& Rinvolucri, 2002). Bu anlamda çeviri, dinleme, konuşma, okuma ve yazmayla birlikte beşinci beceri olarak düşünülebilir (Ferreira Gaspar, 2009). Alma, üretme ve etkileşimle birlikte arabuluculuk (sözlü / yazılı çeviri), Avrupa Dilleri Ortak Çerçeve Programında (CEFR) da açılanan iletişimsel dil etkinlikleri arasındadır. Günümüzün çok kültürlü ve küreselleşmiş toplumu göz önüne alındığında, çeviri yararlı bir dil becerisidir. (G.Cook,2007).Dolayısıyla, öğrencileri dil öğreniminde olumlu yönde motive edici bir özelliğe sahiptir. 


\subsection{Görsel-işitsel çeviri}

Görsel-İsitsel Çeviri, sinema, DVD, TV ve internet gibi medya çeşitlerindeki görsel-işitsel içeriklerin sözlü dilde transferini ifade eder. Genel olarak Görsel-İşitsel çeviri; ekran çevirisi, "multimedya çevirisi, multimodal çeviri veya film çevirisi ni belirtmek için bir şemsiye terim olarak kullanılır (Perego, 2005; Chiaro, 2009). Görsel-işitsel medyanın özelliği, aynı anda işitsel ve görsel kanallar aracılı̆̆ıyla sözlü bir mesaj taşımalarıdır. Son yirmi yılda akademisyenlerin bu alana artan ilgisi sayesinde, bu disiplin artık "Çeviri Çalışmaları alanında en hızlı büyüyen alanlardan biri” olarak kabul edilmektedir (Dỉaz Cintas, 2008). Görsel-Işitsel çeviri iki ana türe ayrılabilir: altyazı (yazılı dil transfer prosedürleri) ve yeniden seslendirme (sözlü dil transfer prosedürleri). Altyazı; diller arası veya dil içi altyazı olabilir; yeniden canlandırma ise dublaj, seslendirme, anlatım, sesli anlatım ve yorumlamayı içerir (Pérez González, 2009).

Altyazılı olacak görsel-işitsel materyaller "çok anlamlı bir metnin parçasıdır" (Pedersen, 2005). Bu nedenle geleneksel çeviride kullanılan yazılı metinlerden farklıdırlar. Sokoli (2006), altyazı çevirisinde görsel-işitsel metninin bir dizi ayırt edici özelliğini tanımlamıştır:

- İki kanal üzerinden alım: akustik ve görsel

- Sözel olmayan unsurların önemli varlığı

- Sözlü ve sözsüz öğeler arasında senkronizasyon

- Ekrandaki görünüm - Tekrarlanabilir malzeme

- Önceden belirlenmiş hareketli görüntü dizisi - Kaydedilen malzeme

Görsel-işitsel metnin dört temel bileşeni, akustik ve sözlü kanalı sözlü ve sözlü olmayan öğelerle birleştirmenin sonucudur: akustik-sözel (diyalog, şarkılar), akustik-sözel olmayan (sesler), görsel sözel olmayan (imgeler) ve görsel-sözel (alt yazılar) ( Diaz Cintas,2008 ). Görsel-işitsel mesajlar orijinal diyaloğun dilsel ve dil dışı özelliklerine odaklanmak için önemli fırsatlar sunar. Filmler ve Televizyon dizileri gibi medya çeşitleri, dil öğrenenlerin dilbilimsel, sosyodilbilimsel ve pragmatik yeterlilik gelişimini teşvik edebilir. Ayrıca bu tür medya çeşitlerini izlemek öğrenciler tarafından rahatlatıcı bulunduğundan onların motivasyonlarını arttırıcı bir özelliğe sahiptir. Görsel-işitsel ortamda kullanılan kaynak dil özellikle yabancı dil öğrenenler için hedef dildeki çeşitli yaş, cinsiyet ve sosyokültürel geçmişe sahip karakterlerin dil kullanımını gözlemleme fırsatını sunar.

Pavesi (2012), görsel-işitsel dilin potansiyelini ortaya çıkarmak için kurgusal ekran diyaloğunda konuşulan İngilizceyi spontane sohbetle karşılaştırarak, derleme temelli bir araştırma yürütmüştür. Çalışmasının odak noktasını, ikinci dil edinimini geliştirmek için "yeterince gerçekçi" olup olmadıklarını doğrulamak amacıyla film ve TV dizilerinin dil özellikleri oluşturmuştur. Pavesi, görselişitsel metnin spontane etkileşime kıyasla kurgusal olmasından dolayı yüz yüze konuşmanın yerini almaması gerektiğini işaret etmektedir. Bununla birlikte görsel-işitsel metinlerin gerçeğe en yakın içerikler olmasından dolayı izleyici için eğitici ve eğlendirici olduğunu belirtmektedir.

Pavesi (2012:158), ikinci dil edinimi için ekran diyaloğunu değerlendirirken iki hususun dikkate alınması gerektiğini belirtir. Birincisi, spontane konuşmaya kıyasla doğallık derecesidir. Ekran diyaloğunun, söylem kalıpları söz konusu olduğunda, öğrencilerin gerçek hayatta muhtemelen 
duyabilecekleri konuşma dilini büyük ölçüde yeniden ürettiğini göstermektedir. İkincisi ise, bir görselişitsel metnin spontane konuşmadan farklı dilsel unsurları içermesidir. Bunlar, ekran diyaloğunu spontane diyalogdan ayrılmakla birlikte, yabancı dil öğrenenler için anlaşılmayı kolaylaştıran unsurlardır. Kurgusal ve spontane konuşma arasındaki en belirgin ilişki, söylem yakınlığı ve öngörülebilirliktir.

Genel olarak, görsel-işitsel söylem standart bir dil çeşitliliğine dayanır ve öğrenciler tarafından daha kolay anlaşılabilir. Zaten, bu tür metinler izleyicilerin rahatça anlamaları ve eğlenebilmeleri amacı taşıdıklarından, mümkün olduğunca sade ve günlük dile en yakın sözcük yapılarıyla kurgulanır. Bu söylem ayarlamaları da yabancı dil öğrenenlerin ekran metnine kolayca adapte olabilmesine yardımcı olur. Bir diğer husus da, üretilen söylemin zaman ve mekâna yakın olaylarla ilgili olmasıdır. Bu nedenle geçmiş zaman cümleleri yerine şimdiki zaman cümlelerini kullanma eğilimi vardır ve üçüncü şahıs zamirleri nadiren bulunur.

Yabancı Dil öğrencileri, özellikle başlangıç düzeyinde, genellikle dilsel formüller edinmeye teşvik edilir. Dilbilgisi kurallarını öğrenme süreci olarak adlandırılan bu dönemde, şayet öğrenciler görsel-işitsel içeriklerle desteklenirse, bu durum öğrencilerin yavaş yavaş formülsel yapının dilbilimsel unsurlarını analiz etmelerine ve daha sonra bu unsurları yaratıcı üretimlerinde kullanmalarına yardımcı olur. Bu da Pavesi'nin araştırmasında ortaya koyduğu görsel-işitsel diyalogların ikinci dil edinimini kolaylaştırıcı etkiye sahip olduğu görüşünü desteklemektedir.

\subsection{Altyazı}

Altyazı, dil öğretiminde ve öğreniminde en çok kullanılan görsel-işitsel çeviri usullerinden biri olmaya başlamıştır. Dỉaz Cintas (2003: 195) tarafından tanımlandığı şekliyle altyazı, genellikle ekranın alt kısmında yazılı metnin görüntülenmesini, oyuncuların diyaloglarının ve görsel görüntünün bir parçasını oluşturan diğer dilbilimsel bilgilerin (harfler, duvar yazıları ve altyazılar) veya film müziği (şarkılar)dil içi ve diller arası yazılı aktarım yöntemidir. Standart altyazılar olarak da adlandırılan diller arası altyazılar, sözlü konuşma dilinin başka bir dile (veya iki başka dile çevrildiği, bu durumda "iki dilli altyazı" olarak adlandırılır) ve basılı metin olarak göründüğü iki dil arasındaki çevirilerdir.

Dil öğrenme amaçları için iki dil arası altyazı kombinasyonu vardır: biri standart altyazıdır (orijinal yabancı dildeki sözlü diyalog anadilde yazılı forma çevrilir) ve diğeri daha az yaygın olan ters altyazıdır (anadildeki diyaloğun yabancı dilde tercüme edilmesi). Öte yandan, dil içi altyazılar, Görsel-işitsel ürünüyle aynı orijinal dil içindedir ve konuşulan metnin yoğunlaştırılmış bir kopyası olarak görünür. Bu tür altyazılara çift modlu altyazılar veya aynı dilde altyazılar da denilmektedir. Dil içi altyazılar genellikle iki tür izleyici tarafından kullanılır: sağır ve işitme güçlüğü çeken bireyler ve dil öğrenen kişiler. Sağır ve işitme güçlüğü çeken bireyler için altyazllar, işitme engelli kişilerin erişemeyeceği konuşma diliyle ilgili bilgileri de içerir.

Mesajı yeniden yapılandırmak için, izleyiciler iki kanalı (sesli ve görsel) kullanırlar ve yalnızca bunları entegre ederek görsel-işitsel içeriği tam olarak anlayabilirler. Görsel-işitsel metnin çok anlamlı doğası nedeniyle çevirmenin fiziksel ve sözel dil arasındaki uyumu sağlayabilmesi gerekmektedir. Kişinin email ikonunu görüp kendisine e-mail geldiğini anlaması gibi dil de sembollerden oluşur. Oysaki gelen sadece onun görüntüsüdür, gerçek mailin kendisi değildir (Koç, 2015: 60). Altyazıcı, görüntüye eşlik edecek sözlü bilgiler ekleyerek izleyicinin mesajı anlamasına yardımcı olmalıdır (Sokoli, 2006).Altyazı 
oluşturma sürecinde zaman ve mekân kısıtlamaları, kelimesi kelimesine tercümeyi imkânsız kılar. Bu nedenle alt yazıcı temel mesaja odaklanmaya ve anlamı mevcut yer ve zamana göre iletmeye zorlanır.

Son yirmi yılda akademisyenler tarafından altyazıların kullanımı üzerine yapılan kapsamlı araştırmalar, diller arası altyazıların başlangıç seviyesindeki öğrenciler için daha uygun olduğunu, dil içi altyazıların da ileri düzey için daha uygun olduğunu göstermiştir. (Danan, 2010:Talaván, 2012). Daha teknik bir düzeyde, diller arası altyazılar film veya TV programında olma eğilimindedir ve her zaman görünürdür. Bu nedenle, açı altyazı olarak bilinirken, dil içi altyazılar isteğe bağlı olduklarından ve bu nedenle yalnızca izleyici tarafından seçildiğinde görünür olduklarından kapalı altyazı olarak adlandırılırlar.

Altyazı, somut bir sonucu olan motive edici, görev temelli bir faaliyettir ve hem yüz yüze hem de çevrimiçi öğrenme bağlamlarında bireysel olarak veya grup çalışmasıyla gerçekleştirilebilir. Dil öğreniminde altyazı, diller arası veya dil içi olabilir. Dil arası altyazı standart (yabancı dilden anadile) veya ters çevrilebilir (anadilden yabancı dile). Standart altyazı süreci, mesajı dilsel ve kültürel açıdan uygun bir şekilde kişinin yazılı anadilinde iletebilmek için yabancı dildeki görsel-işitsel girdisinin anlaşılmasını gerektirir. Bu tür altyazı, ister diller arası altyazılar videoya gömülü olsun, ister orijinal diyalog yazıya aktarılmış olsun, yabancı dilde dinlediğini anadilde okuduğunu anlamayı geliştirir.

Tersine altyazı, öğrencilerin sözlü bir anadil metni yazılı bir yabancı dile çevirisini sağlamalarını gerektirir. Bu çeviri görevi, yabancı dilde yazılı ifade edebilme yeteneğini geliştirir. Tersine altyazı öğrencilerin, orijinal metnin yabancı dilde deyimsel ve kültürel nüanslarıyla tutarlı metinler üretebilmeyi gerektiren bir aracılık faaliyetidir. Hem standart hem de çevrilmiş altyazı, sözlü girdinin diğer iki dile çevrilmesi faaliyeti olduğundan, çok dilli bir öğrenme ortamı meydana getirir.

Dil içi altyazı çeviriyi içermese de, yabancı dil sınıflarında herhangi bir dilde özetleme ve açıklama becerilerini geliştirmek için alıştırma olarak kullanılabilir. Örneğin, profesyonel eğitimde, herhangi bir altyazı faaliyetinden önce, Dīaz Cintas (2008) öğrencilerden özet üretmelerini istemeyi önerir. Bu, iletilecek ana fikirleri aramaları ve ardından bu fikirleri doğal bir şekilde yeniden ifade etmeleri gerektiğinden, kelime kelime çeviri fikrini reddetmelerine neden olan bir alıştırmadır. Bu hazırlık alıştırması hem anadilde hem de yabancı dilde dil öğrenenler için etkili bir şekilde kullanılabilir. Yabancı dilde iki modlu altyazı, bir metni ikinci bir dilde yeniden biçimlendirmenin karmaşıklığından dolayı ileri düzey öğrenciler tarafindan gerçekleştirilmesi daha uygun olurken, anadilde de çift modlu altyazı kullanımı herhangi bir altyazı uygulamasına giriş seviyesinde tercih edilebilir.

\section{Yabancı dil eğitiminde görsel-işitsel çevirinin etkileri}

Zojer (2009), bir öğretim aracı olarak çevirinin sağladığı bazı avantajları sıralamıştır;

1. Çeviri, gerçek hayattaki dil kullanımına daha yakın bütüncül bir etkinliktir,

2. Çeviri, kaçınma stratejilerine izin verilmediği için öğrencileri dil alanlarını genişletmeye zorlar.

3. Çeviri süreci, bireyi farklı kelimeleri etkili bir şekilde kullanmaya zorlar,

4. Çeviri öğrencilerin okuma ve anlama stratejilerini geliştirmelerini sağlar, 
5. Çeviri sözdizimsel, anlambilimsel ve metinsel kavrama yeteneklerinin gelişmesine katkı sağlar,

6. Çeviri, öğrencilerin Anadildeki yeterliliklerini arttırır;

7. Çeviri ile anadil ve hedef dilin içinde bulunduğu kültürel değerlerin etkileşiminin incelenmesine olanak sağlar,

8. Çeviri aktarılabilir becerilerin kazanılmasını teşvik eder;

Bir arabuluculuk faaliyeti olarak çeviri, öğrencilerin mesleki veya özel yaşamlarında kullanılabilir. Tüm bu olumlu unsurlar altyazıyla da genişletilebilir. Altyazının başlıca avantajları, söz konusu çeviriyle ilgili olanlardır. Altyazı dört görsel-işitsel beceri içerir: Görsel-işitsel izleme (sözel ve sözel olmayan sinyallerin karmaşık bir kombinasyonu yoluyla aktarılan anlamın anlaşılması); Görsel-işitsel dinleme (Görsel-işitsel metnin görsel ve diğer unsurlarıyla bağlantılı olarak sözlü öğelerin kavranması); Görselişitsel yazma (Görsel-işitsel metnin altyazısı) ve Görsel-işitsel okuma (Görsel-işitsel metnin yazılı olarak anlaşılması).

Ancak, altyazı oluşturma sürecinde öğrenciler sadece kaynak metni hedef metne çevirmekle kalmaz, aynı zamanda bir medya mesajını izler ve dinlerler. Bu bağlamda, Zabalbeascoa ve ark. (2012); yabancı dil ediniminde geleneksel olarak hedeflenen ve Ortak Avrupa Çerçevesi tarafından benimsenen; okuma, yazma, dinleme ve konuşma becerisi elde etmenin kısıtlayıcı olduğunu belirtmişler ve günümüzde bu becerilere görsel-işitsel iletişim becerileri tanımının da eklenmesi gerektiğini söylemişlerdir. Bu nedenle, altı görsel-işitsel beceri tanımlayarak geleneksel 4 beceri tanımının genişletilmesini önerirler: Görsel-işitsel izleme, Görsel-işitsel dinleme, Görsel-işitsel okuma, Görsel-işitsel konuşma, Görsel-işitsel yazma ve Görsel-işitsel üretim.

Altyazı uygulamaları, yabancı dil sınıflarında eğitim faaliyetlerine dâhil edildiğinde olumlu sonuçlar meydana getirebilir. Motive edici bir faaliyet olmanın yanı sıra, bireysel ve işbirlikçi öğrenmeye de olanak tanır. Altyazı çevirisinde, öğrencilerin yer ve zaman kısıtlamalarını da dikkate alması gerekir. $\mathrm{Bu}$ bağlamda, kelime çevirisi oldukça zordur, çünkü kelime çevirisi karakter sayısını ve izin verilen okuma süresini aşacaktır. Altyazı çalışmaları; mesaja yoğunlaşma, anlam için odaklanma, bazı bilgileri kısmen azaltma veya atlamaya karar verme süreçlerini gerektirdiğinden öğrenciler için mükemmel bir egzersizdir (Lertola, 2015).

Bir alıcı ve arabuluculuk faaliyeti olarak, altyazı çevirisi hedef dilde dinlediğini anlamayı teşvik eder (Talaván, 2010, 2011; Talaván ve Rodrīguez-Arancón, 2014), bununla beraber hedef dilde yazma becerilerini, kelime edinimini ve kültürel farkındalık bilincinin gelişmesine katkı sağlar (Williams ve Thorne, 2000; Bravo, 2010; Lertola, 2012). Öğrencilerin altyazı görevini yerine getirebilmeleri için çeviri deneyimine sahip olmaları gerekmeyebilir ancak çalıştıkları yabancı dil hakkında yeterli bilgiye sahip olmaları gerekir.

Yabancı Dil eğitimi bağlamında, dil kombinasyonları dinleme ve okuduğunu anlama, telaffuz ve kelime bilgisini geliştirmek için kullanılabilir. Örneğin, diller arası altyazı, dinlediğini anlama becerisini geliştirmek için (Talavan,2013) veya kültürlerarası dil eğitimi (Borghetti ve Lertola, 2014) için kullanılabilir, dil içi dublaj akıcılığı ve telaffuzu geliştirmek için (Sánchez-Requena, 2016), yabancı dilde yayınlanan reklamlar da sözcüksel ve deyimsel yeterlilik üzerinde çalışmak için kullanılabilir (Ibáñez \& Vermeulen, 2013). 
Baños ve Sokoli (2015), Görsel-işitsel çevirinin çeşitliliği ortaya çıkardığını, etkileşimli ve eğlenceli bir öğrenme ortamı yaratarak öğrencilerin motivasyonunu artırdığını, sözel olmayan kültürel unsurlara maruz kalmaya neden olarak iletişimin özgün dilbilimsel ve kültürel yönlerine erişebilmeye olanak sağladığını belirtmektedir. Görsel-işitsel materyaller, yabancı dil eğitimine esneklik sağlamaktadır ve hem öğrencilerin hem de öğretmenlerin ihtiyaçlarına göre uyarlanabilir. Incalcaterra McLoughlin ve Lertola (2014), Görsel-işitsel çeviri kullanımının dil derslerine geleneksel çeviriden daha olumlu katkılar sağladığına işaret etmektedir. Örneğin; akılda tutmayı kolaylaştırır, kültürel ve kültürlerarası konular ile iletişimin pragmatik yönleri hakkında farkındalık yaratmaya yardımcı olur, motivasyonu artırır ve genel öğrenme deneyimini geliştirir.

\section{Sonuc}

Dil öğreniminde Görsel-işitsel çeviri üzerine yapılan araştırmalar sınırlıdır. Bunlar arasından Williams ve Thorne (2000) ile Bravo (2008)'nun çalışmaları örnek olarak gösterilebilir. Bravo (2008), yabancı dil eğitimi olarak İngilizce dersi alan bir grup Portekizli öğrenci üzerinde, alt başlık oluşturma aracılı̆̆ıyla yaptı̆̆ı çalışmada, görsel-işitsel çeviri eğitimi alan katılımcıların, kelime anlamını hızlı ve üretken bir şekilde hatırlayabildiklerini belirtmektedir. Bravo'nun araştırması, anında tanımanın yanı sıra gecikmiş üretken hatırlama ve deyimsel akılda tutmanın bağlam içinde kullanımına odaklanmaktadır. Her iki çalışmanın da bulgularında dil öğrenimi olarak altyazı uygulamasının öğrencilerin kelime dağarcığını arttırdığı, kullanılan görsel-işitsel materyallerdeki cümlelerden kendi amaçlarına göre uyarlamalar yapabildiklerini göstermiştir. Aynı zamanda, öğrencilerin çalışmaları esnasında anadil ve yabancı dildeki kelimelerin eşdeğerliklerini uygun bir şekilde sağlayabildikleri sonucuna ulaşmışlardır.

Yabancı Dil Sınıflarında Görsel-İşitsel Çeviri, şu anda geniş çapta kabul görmekte ve dil öğretmenleri, akademisyenler ve yabancı dil öğrencileri tarafından çeviri uygulamaları dil öğrenmenin sürekliliği ve kalıcılığı açısından en etkili araçlardan biri olarak kabul edilmektedir. Bu fikir aynı zamanda, dil etkinliklerini üretim (sözlü ve yazılı), alımlıma (işitsel, görsel ve görsel-işitsel), etkileşim (sözlü ve yazılı) ve arabuluculuk açısından ayıran Ortak Avrupa Dil Referans Çerçevesi (CEFR) tarafindan da onaylanmıştır. (Avrupa Konseyi, 2001). Bu, geleneksel dört beceri modelinin (dinleme, okuma, konuşma ve yazma) bir çeşididir. CEFR yeni bir alımlıma becerisi sunar: öğrencinin görsel ve işitsel duyuları aracılığıyla örneğin yüksek sesle okunan bir metni takip etmek, altyazılı TV, video veya film izlemek, multimedya ve dijital teknolojilere dayalı eş zamanlı öğrenme yöntemi. "(Avrupa Konseyi, 2001, s.71). Bu açıdan çeviri, yabancı dil çalışmasında geliştirilmesi gereken temel bir iletişim becerisi olarak düşünülebilir.

Görsel-İşitsel çeviri'nin yabancı dil derslerine dâhil edilmesi, hayatımızın vazgeçilmez bir parçası haline gelen dizüstü bilgisayar, tablet ve cep telefonu gibi ekran cihazlarının kullanımıyla da bağlantılıdır. Yabancı Dil öğretiminde, geleneksel karatahtalar yerini bilgisayarlara ve etkileşimli tahtalara bırakmıştır. (Leask ve Pachler, 2014). Teknolojik ilerlemeler, bilim insanlarının Bilgisayarlı İletişim Teknolojileri'nin eğitim çalışmalarına uyarlanması hususunda daha fazla araştırma yapmaya yöneltmiştir. Witte vd. (2009, s. 5), "esnek ve yenilikçi öğretim yöntemleriyle birleşen yeni teknolojiler, çeviri alıştırmaları yoluyla öğrenmenin çok motive edici olduğunu” hususunun altını çizmişlerdir.

Yapılan çalışmalar, yabancı dil eğitiminde çeviri ve teknoloji doğru kullanıldığında geleneksel öğretim yöntemlerini tamamlayabileceğini, yabancı dil öğrenme seçeneklerinin çeşitliliğini artırabileceğini ve 
öğrenmeyi kolaylaştırabileceğini ortaya koymaktadır. Buna ek olarak, öğrenciler, yapmış oldukları tercüme sürecinde yabancı dildeki dilsel ve kültürel özellikler hakkında da bilgi sahibi olma imkânı da elde edebilirler.

Yabancı dil sınıflarında görsel-işitsel çeviri yöntemlerini kullanmak kuşkusuz öğrencileri motive edici ve eğlendirici bir yöntemdir. Öğrenciler öğrenirken eğlenmekte ve daha güçlü öğrenci-öğretmen ve öğrenci-öğrenci bağları yaratmaktadır. Ayrıca, görsel-işitsel çeviriyi kullanmak eğitimcilere ve öğrencilere teknolojik ilerlemeyi takip etmek için iyi bir gerekçe olmaktadır ve öğrencilerin bilgisayar teknolojileri becerilerini ve grup çalışma becerilerini geliştirmelerine de katkı sağlamaktadır. Bütün bu değerlendirmeler ışığında, görsel-işitsel çeviri uygulamalarının yabancı dil sınıflarında müfredata dâhil edilmesi; hem dijital medya okuryazarlığının gelişmesi hem de yabancı dil edinimi açısından faydalı olacă̆ı sonucuna ulaşılmıştır.

\section{Kaynakça}

Atkinson, David (1987). "The mother tongue in the classroom. a neglected resource?", ELTJournal. Vol.41(4). 241-247.

Banos, R., \& Sokoli, S. (2015). Learning foreign languages with ClipFlair: using captioning and revoicing activities to increase students' motivation and engagement. In K. Borthwick, E. Corradini \& A. Dickens (Eds), 10 years of the LLAS elearning symposium: case studies in good practice(pp. 203-213). Research-publishing.net. https://doi.org/10.14705/rpnet.2015.000280

Bollettieri, Rosa M.; Digiovanni, Elena; Rossato, Linda (2014). "New challenges in audiovisual translation". In: Bollettieri Bosinelli, R. M., \& Di Giovanni, E. \& Rossato, L. (Eds.), inTRAlinea Special Issue: Across Screens Across Boundaries. From http://www.intralinea.org/specials/article/new_challenges_in_audiovisual_translation (erişim tarihi 22 Temmuz 2020).

Borghetti, Claudia (2011). "Intercultural learning through subtitling: The cultural studies approach". In: Incalcaterra McLoughlin, L. \& Biscio, M. \& Nī Mhainnīn, Mairin A. (Eds.), Audiovisual translation subtitles and subtitling. Theory and practice.Bern: Peter Lang. 111-137.

Borghetti, Claudia \& Jennifer Lertola (2014). "Interlingual subtitling for intercultural language education: a case study".Language and Intercultural Communication.Vol.14(4). 423-440.

Bravo, Carolina. (2008). Putting the reader in the picture: screen translation and foreign-language learning. Doctoral Thesis. http://www.tesisenred.net/handle/10803/8771

Chiaro, Delia (2009). "Issues in audiovisual translation". In: J. Munday (Ed.), The Routledge Companion to Translation Studies.London: Routledge. 141-165.

Cook, Guy (2007). "A thing of the future: translation in language learning". International Journal of Applied Linguistics. Vol.17(3). 396-401.

Cook, Guy, (2010). Translation in language teaching: An argument for reassessment. Oxford: Oxford University Press.

Council of Europe (2001). Common European Framework for Languages: Learning, Teaching, Assessment.Cambridge: Cambridge University Press.

Danan, Martine (2010). Dubbing projects for the language learner: a framework for integrating audiovisual translation into task-based instruction. Computer Assisted Language Learning, 23(5), 441-456. 
Deller, Sheelagh \& Mario Rinvolucri (2002). Using the mother tongue: making the most of the learner' s language.London: Delta Publishing

Diaz Cintas, Jorge (2008). "Introduction. The didactics of audiovisual translation". In: J. Dīaz Cintas (Ed.), The Didactics of Audiovisual Translation.Amsterdam: John Benjamins. 1-18.

Ek, Jan A. \& John L. M. TR I M(1990). Threshold 1990. Cambridge: Cambridge University Press.

Ferreiragaspar, Neide (2009). "Translation as a fifth skill in EFLclasses at secondary level". In: Witte, A. \& Harden, T. \& Ramos de Oliveira Harden, A. (Eds.), Translation in Second Language Learning and Teaching. Bern: Peter Lang. 173-179.

Finocchiaro, Marry., \& Brumfit, Christopher. (1983). The Functional-=otional Approach: From Theory to Practice. New York: Oxford University Press.

Fries, Charles C. (1945). Teaching and learning english as a foreign language.Ann Arbor, MI: University of Michgan Press.

Harold D. Palmer (1917) The Scientific Study and Teaching of Languages, by, University College, London.

Holmes, James (1972). The name and nature of translation studies. In: J. Holmes, Translated papers on literary translation and translation studies (pp. 67-80). Amsterdam: Rodopi

Howatt \& Richard Smith (2014) The History of Teaching English as a Foreign Language, from a British and European Perspective, Language \& History, 57:1, 75-95.

Hymes, Dell (1972). "On communicative competence". In: Pride, J. B. \& Holmes, J. (Eds.), Sociolinguistics. London: Penguin. 269-293.

Incalcaterra McLoughlin, Laura., \& Lertola, Jennifer. (2014). Audiovisual translation in second language acquisition: integrating subtitling in the foreign language curriculum. Special issue of The Interpreter and Translator Trainer, https://doi.org/10.1080/1750399X.2014.908558.

Ibanez Moreno, \& Vermeulen, Anna (2013). Audio description as a tool to improve lexical and phraseological competence in foreign language learning. In D. Tsigari \& G. Floros (Eds), Translation in language teaching and assessment(pp. 41-61). Cambridge Scholars Publishing.

Incalcatera McLoughlin, Laura \& Jennifer Lertola(2015). "Captioning and revoicing of clips in foreign language learning-Using ClipFlair for teaching Italian in online learning environments". In: C. Ramsey-Portolano (Ed.), The Future of Italian Teaching.Newcastle upon Tyne: Cambridge Scholars Publishing. 55-69.

Jespersen, Otto (1904). How to teach a foreign language.London: George Allen and Unwin.

Koç, N . (2015). Identity Politics . International Journal of Media Culture and Literature , 1(2),5765Retrieved from https://dergipark.org.tr/tr/pub/ijmcl/issue/31751/348019.

Lado, Robert (1957). Linguistics across cultures. Applied linguistics for language teachers. Ann Arbor: University of Michigan Press.

Laviosa, Sara \& Valerie Cleverton (2006). "Learning by translating: A contrastive methodology for ESPlearning and translation".Journal of the Slovene Association of LSOTeachers-Scripta Manent. Vol.2(1). 3-12.

Leask, Marilyn \& Pachler, Norbert (2014). Learning to teach using ICT in the secondary school: a companion to school experience. London: Routledge, Taylor, \& Francis Group. 
Lertola, Jennifer (2015). "Subtitling in language teaching: Suggestions for language teachers". In: Gambier, Y. \& Caimi, A. \& Mariotti, C. (Eds.), Subtitles and Language Learning. Bern: Peter Lang. 245-267.

Malmkjaer, Kirsten (Ed.) (1998). Translation and language teaching: language teaching and translation.Manchester: St. Jerome Publishing.

Mayoral, Rafael (2002). Nuevas perspectivas para la traducción audiovisual. (New perspectives for audiovisual translation). Sendebar, 13, 123-140.

Newmark, Peter (1988). A textbook of translation. New York and London: Prentice Hall.

Pavesi, Marco (2012). The potentials of audiovisual dialogue for second language acquisition. In P. Alderete-Dīez, L. Incalcaterra McLoughlin, L. NīDhonnchadha \& D. NīUigin (Eds), Translation, technology and autonomy in language teaching and learning(pp. 155-174). Peter Lang.

Pedersen, Jan (2005) How is culture rendered in subtitles? In S. Nauert (ed.) Proceedings of the Marie Curie Euroconferences 'MuTra: Challenges of Multidimensional Translation', Saarbrucken, 26 May 2005. www.euroconferences.info/proceedings/ 2005_Proceedings/2005_Pedersen_Jan.pdf

Perez Gonzalez, Luis (2009). «Audiovisual translation». In: Baker, M. \& Saldanha, G. (Eds.), Routledge Encyclopedia of Translation Studies (2nd ed.). 13-20.

Richards, Jack C. \& Theodore S. Rodgers (2001) Approaches and methods in language teaching(2nd ed.). Cambridge: Cambridge University Press.

Sanches Requena, Alicia (2016). Audiovisual translation in teaching foreign languages: contributions of dubbing to develop fluency and pronunciation in spontaneous conversations. Porta Linguarum, 26, 9-21. https://www.ugr.es/ portalin/articulos/PL_numero26/ART1_Alicia\%20Sanchez.pdf

Skinner, Burrhus Frederic (1957). Verbal behavior. New York: Appleton.Cambridge: Cambridge University Press.

Sokoli, Stavroula (2006). "Learning via Subtitling (LvS)". A tool for the creation of foreign language learning activities based on film subtitling. Paper presented at the Multidimensional translation: Audiovisual translation scenarios, Copenhagen. From

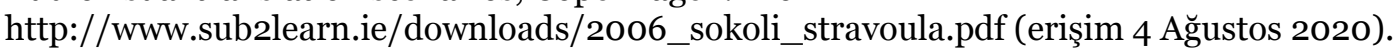

Sokoli, Stavroula; Zabalbeascoa, Patrick; Fountana, Maria (2011). «Subtitling activities for foreign language learning: what learners and teachers think». In: Incalcaterra McLoughlin, L. \& Biscio, M. \& Ní Mhainnín, M. Á. (Eds.), Audiovisual Translation Subtitles and Subtitling. Theory and Practice. Bern: Peter Lang. 219-242.

Stoddart, Jonathan (2000). "Teaching through translation". British Council Journal. Vol.11. 6-12.

Sweet, Henry (1899), The Practical Study of Languages: A Guide for Teachers and Learners. Language and Language Learni:g [Series], Number 1. Oxford University Press.

Talavan, Noa (2010). "Subtitling as a task and subtitles as support: Pedagogical applications". In: Dīaz Cintas, J. \& Matamala, A. \& J. Neves (Eds.), New Insights into Audiovisual Translation and Media Accessibility. Amsterdam: Rodopi. 285- 299.

Talavan, Noa (2011). "A quasi-experimental research project on subtitling and foreign language acquisition». In: Incalcaterra McLoughlin, L. \& Biscio, M. \& Ní Mhainnín, M. A. (Eds.), Audiovisual translation subtitles and subtitling. Theory and practice.Bern: Peter Lang. 197-217.

Talavan, Noa (2013). La subtitulación en el aprendizaje de las lenguas extranjeras. Octaedro

Talavan, Noa \& Pilar Rodriguez-Arancon (2014). «The use of interlingual subtitling to improve listening comprehension skills in advanced EFLstudents». In: Garzelli, B. \& Baldo, M. (Eds.), 
Subtitling and Intercultural Communication. European Languages and Beyond. Pisa: InterLinguistica, ETS. 273-288.

Talavan,Noa, Avila-Cabrera, Jose, Javier \& Costal, Tomas. (2016). Traducción y accesibilidad audiovisual. (Audiovisual translation and accessibility). Barcelona: UOC

Trim, John Leslie Melville (2007). Modern languages in the Council of Europe, 1954-1997. Strasbourg, France: Council of Europe. From; http://www.coe.int/t/dg4/linguistic/Source/TRIM_21janv2007_EN.doc (erişim 28 Temmuz 2020).

Wilkins, David Arthur (1972). Linguistics in Language Teaching. London: Arnold.

Wilkins, David Arthur (1976). Notional Sylllabuses. Oxford: Oxford University Press.

Williams, Helen \& David Thorne (2000). "The value of teletext subtitling as a medium for language learning". System. Vol.28(2). 217-228.

Witte, Arnd; Harden,Theo; Ramos de Oliveira Harden, Alessandra (Eds.). (2009). Translation in Second Language Learning and Teaching.Bern: Peter Lang.

Zabalbeascoa, Patrick; Sokoli,Stavroula; Torres, Olga(2012). «CLIPFLAIRforeign language learning through interactive revoicing and captioning of clips. Lifelong Learning Programme - Key Activity 2. Languages, Multilateral Project. D2.1. Conceptual framework and pedagogical methodology».http://clipflair.net/wp-content/ uploads/2014/06/D2.1ConceptualFramework.pdf (erişim tarihi 12 Temmuz 2020).

Zojer, Heidi (2009). «The methodological potential of translation in second language acquisition: Reevaluating translation as a teaching tool». In: Witte, A. \& Harden, T. \& Ramos de Oliveira Harden, A. (Eds.), Translation in Second Language Learning and Teaching. Bern: Peter Lang. 31-51. 